\title{
The adhesive system and root canal region do not influence the degree of conversion of dual resin cement
}

\author{
Priscilla Cristoforides PEREIRA ${ }^{1}$, Renata Marques de MELO², Carolina CHAVES ${ }^{3}$, Graziela A. P. GALHANO², \\ Marco Antonio BOTTINO ${ }^{4}$, Ivan BALDUCCI ${ }^{5}$
}

\begin{abstract}
1- Research Fellow, Department of Dental Materials and Prosthodontics, São José dos Campos Dental School, São Paulo State University, São José dos Campos, SP, Brazil.

2- DDS, PhD student, Department of Dental Materials and Prosthodontics, São José dos Campos Dental School, São Paulo State University, São José dos Campos, SP, Brazil.

3- DDS, DMD, PhD student, Dental Materials and Prosthodontics, Araraquara Dental School, São Paulo State University, Araraquara, SP, Brazil.

4- DDS, DMD, Professor, Department of Dental Materials and Prosthodontics, São José dos Campos Dental School, São Paulo State University, São José dos Campos, SP, Brazil.

5- DDS, DMD, PhD, Professor, Department of Social Science and Pediatric Dentistry, São José dos Campos Dental School, São Paulo State University, São José dos Campos, SP, Brazil.
\end{abstract}

Correspnding address: Renata Marques de Melo - DMOP - Av. Engenheiro Fco. José Longo, 777 - $12245-200$ - São Dimas - São José dos Campos, SP Brasil - Phone: (12) 3947-9060 - e-mail: marquesdemelo@gmail.com

Received: February 25, 2009 - Modification: September 28, 2009 - Accepted: February 16, 2010

\section{ABSTRACT}

\begin{abstract}
$\mathrm{O}$ bjectives: The aim of this study was to evaluate the influence of two adhesive systems and the post space region on the degree of conversion of dual resin cement and its bond strength to root dentin. Material and Methods: One three-step etch-andrinse (All-bond 2, Bisco) and another one-step self-etch (Xeno III, Dentsply) adhesive systems were applied on $20(n=10)$ crownless bovine incisors, at 12-mm-deep post space preparation, and a fiber post (FRC Postec, Ivoclar) was cemented using a dual cure resin cement (Duo-Link, Bisco). Three transverse sections (3 $\mathrm{mm}$ ) were obtained, being one from each study region (cervical, middle and apical). The degree of conversion of the dual cure resin cement was determined by a micro-Raman spectrometer. The data (\%) were submitted to repeated-measures analysis of variance and Tukey's test $(p<0.05)$. Results: For both groups, the degree of conversion means $(\%)$ (All bond $2_{\text {cervical }}=69.3$; All bond $2_{\text {middle }}=55.1$; All bond $2_{\text {apical }}=56$; Xeno III cervical $=68.7$; Xeno III middle $=68.8$; Xeno III apical $=$ $54.3)$ were not significantly different along the post space regions $(p<0.05)$. Conclusions: Neither the adhesive nor the post space region influenced the degree of conversion of the cement layer.
\end{abstract}

Key words: Root canal. Resin Cements. Raman spectroscopy. Adhesives.

\section{INTRODUCTION}

Many studies about the hybridization of the root canal dentin are conclusive with respect to the factors that can lead to poor bonding in this environment. It is known that the cavity configuration and the dentin structure of the root canals make hybridization difficult. However, the effects of other factors such as the type of adhesive have been scarcely explored.

The cavity configuration is one of the most critical variables in bonding to the root canal dentin. Even though the $C$ factor varies from 1 to 5 in coronal restorations, it might be higher than 200 when posts are luted in the three-dimensional environment of the root canal ${ }^{2}$. Another problem is the dentin root canal structure. Usually, the root dentin tubules are straighter, less divergent and less dense than in the coronal dentin ${ }^{6,12}$. Because of the increasing use of fiber posts associated to dual cure resin adhesive materials the discussion was also turned towards the polymerization of the resin cement along the root canal ${ }^{15,19}$.

Therefore, one must always consider such issues when using resinous materials in the root canal. The remaining factors such as the behavior of dental adhesives on dentin depend mostly on the material used. Currently, several presentations of dentin adhesives are available: total dentin etching with previous acid etching followed by primer and adhesive applied separately (three-step systems) 
or in combination (two-step systems); and selfetch systems, which contain a self-etching primer and an adhesive, separately (two-step systems) or in one solution (all-in-one systems). The increasing preference for using simplified systems (two-step total-etch and all-in-one self-etch systems) is due to the shortening of chair time. However, for a number of reasons, the use of these materials is always harmful to bonding when compared to multi-bottle materials (three-step etch-and-rinse and two-step self-etch systems $)^{4,17,18}$. One reason is that the acidic monomers present in the oxygeninhibited layer of one step-self-etch adhesives are brought in direct contact with the chemicalor dual-cure composite, titrating the basic amine accelerators and inactivating them ${ }^{4,8,16}$.

Concerning the methods to determine the degree of conversion of dental composites, the most commonly used are indirect analyses by means of flexural and hardness test, differential scanning calorimetry and direct analyses using infrared spectroscopy (FTIR) or Raman spectroscopy. Microspectroscopy is obtained by using the spectroscope with a microscope, and can be used to analyze microscopic samples. In dentistry, this technique has been mainly used to evaluate the degree of conversion of methacrylate resins in the initial stages of polymerization ${ }^{14}$.

Most studies about the incompatibility between simplified adhesive systems and dual cure resin cements measured the bond strengths at the dentin/adhesive/cement interfaces ${ }^{1,4,8,11}$. However, no investigation determining the degree of conversion in situ has ever been conducted. With the recent interest in bondable root-filling materials to intraradicular dentin, such analysis is also of clinical importance to prevent debonding of the restoration. Therefore, this study evaluated the influence of two adhesives systems (all-inone self-etch and three-step etch-and-rinse) and root canal regions on the degree of conversion of dual cure resin cement by means of micro-Raman analysis. It was hypothesized that the degree of conversion would be lower for the self-etch group in the deepest levels of the post space.

\section{MATERIAL AND METHODS}

Twenty bovine lower incisors were extracted and stored in distilled water at $-4^{\circ} \mathrm{C}$. They were randomly divided into two groups $(n=10)$, according to the adhesive system (Figure 1 ).

The root lengths were standardized at $16 \mathrm{~mm}$. The teeth had their root canals prepared with a low speed calibrated drill (size 2) of a glass- FRC post system (FRC Postec, Ivoclar, Schaan, Lichtenstein) at a working length of $12 \mathrm{~mm}$. The remaining 4 $\mathrm{mm}$ were sealed with gutta-percha. Afterwards, the outer surface of each tooth was covered with black nail varnish to allow passage of light only through the most coronal portion.

The adhesive application followed the

\begin{tabular}{|c|c|c|}
\hline $\begin{array}{c}\text { Material } \\
\text { (manufacturer) }\end{array}$ & Composition & Application procedures \\
\hline $\begin{array}{l}\text { All Bond } 2 \text { (Bisco Inc., } \\
\text { Schaumburg, IL, USA) }\end{array}$ & $\begin{array}{c}\text { Primer A: Acetone, Ethanol, Na-N- } \\
\text { totylglycine glycidylmethacrylate; } \\
\text { Primer B: Acetone, Ethanol, Biphenyl } \\
\text { dimethacrylate; } \\
\text { Pre-Bond resin: Bisphenol A } \\
\text { diglycidymethacrylate, Triethyleneglycol } \\
\text { dimethacrylate, Benzoyl Peroxide }\end{array}$ & $\begin{array}{l}\text { 1- Etch with } 32 \% \text { phosphoric acid (UNI-ETCH, Bisco } \\
\text { Co., Schaumburg, IL, USA for } 15 \mathrm{~s} \text {. } \\
\text { 2- Water rinse. } \\
\text { 3- Dry with absorbent paper points (\#80). } \\
\text { 4- Apply Primer A + B with a microbrush (SDI BRASIL } \\
\text { INDÚSTRIA E COMÉRCIO LTDA., São Paulo, SP, } \\
\text { Brazil). } \\
\text { 5- Apply "Pre-Bond resin" with a microbrush. }\end{array}$ \\
\hline $\begin{array}{l}\text { Xeno III (Dentsply } \\
\text { DeTrey, Konstanz, } \\
\quad \text { Germany) }\end{array}$ & $\begin{array}{c}\text { Universal: 2-Hydroxiethyl methacrylate, } \\
\text { aerosol R947, 2,6-di-tert-butyl-p-cresol, } \\
\text { ethanol (BHT), water } \\
\text { Catalyst: tetra-metacryl-ethyl-pyrophosphate, } \\
\text { Penta-methacryl-oxy-ethyl-cyclo- } \\
\text { phosphazen-monofluoride, Urethane } \\
\text { dimethacrylate, BHT, camphorquinone, } \\
\text { p-dimethyl amine ethyl benzoate }\end{array}$ & $\begin{array}{l}\text { 1- Mix Universal liquid and Catalyst. } \\
\text { 2- Apply and leave undisturbed for } 20 \mathrm{~s} \text {. } \\
\text { 3- Air dry } \\
\text { 4- Light-cure for } 10 \mathrm{~s} \text {. }\end{array}$ \\
\hline $\begin{array}{l}\text { DUO-LINK (Bisco Inc., } \\
\text { Schaumburg, IL, USA) }\end{array}$ & $\begin{array}{l}\text { Bisphenol A diglycidyl methacrylate }(5-30 \%) \\
\text { Triethyleneglycol dimethacrylate }(5-20 \%) \\
\text { Glass filler }(50-80 \%) \\
{ }^{* *} \text { Urethane dimethacrylate }(5-15 \%) \\
{ }^{* *} \text { Base only }\end{array}$ & $\begin{array}{l}\text { 1- Mix equal amounts of DUO-LINK base and catalyst } \\
\text { into a uniform paste for } 10 \mathrm{~s} \text {. } \\
\text { 2- Carry the cement into the canal with a lentulo } \\
\text { spiral. } \\
\text { 3- Light-cure for } 40 \text { seconds. }\end{array}$ \\
\hline
\end{tabular}

Figure 1- Materials tested in the study 
manufacturer instructions (Figure 1). The cement was then applied to the root canal with a Lentulo No 40 spiral (Dentsply Maillefer, Tulsa, Oklahoma, USA), the FRC Postec post (Ivoclar) was positioned and the set was light-cured through the post for 40 s (Optilight 600; Gnatus Equipamentos MédicoOdontológicos LTDA, Ribeirão Preto, SP, Brazil) at a light intensity of $600 \mathrm{~mW} / \mathrm{cm}^{2}$. Afterwards, the teeth were sectioned perpendicular to their long axis with a diamond saw (Microdont, São Paulo, SP, Brazil) under water irrigation. The first 0.5 $\mathrm{mm}$ section was discarded because of the excess cement. Three segments measuring nearly $3 \mathrm{~mm}$ were obtained, being one from each study region (cervical, middle and apical regions of the root canal preparation).

The specimens were stored in distilled water at $37^{\circ} \mathrm{C}$ for $48 \mathrm{~h}$. The degree of conversion was determined with a computer-controlled Raman Microscope (System-2000, Renishaw, Wottonunder-Edge, Gloucestershire, UK). Each root section was excited at a wavelength of $514 \mathrm{~nm}$ by an Ar laser through an optical microscope. The specimen was placed on the $X-Y$ stage and the laser beam was focused on the specimen surface through a 50x microscope objective with $1 \mu \mathrm{m}$ of lateral spatial resolution. After calibration of Raman shift frequency, using known lines of silicon, both the spectra of the base paste of the cement (uncured) (Figure 2) and the spectra of the cement in the post space (cured) (Figures 3 and 4) were obtained (spectral range: $1500-1800 \mathrm{~cm}^{-1}$ ). The dual-cure resin cement was scanned in three different points approximately at $1 \mu \mathrm{m}$ distance from the hybrid layer and equidistant to one another.

The analyses of the acquired spectra were made using Origin 7.0 with Peak Fitting module (Microcal Software Inc., Northampton, MA, USA), which is a curve fitting program. The measurement of residual double bonds was made on a relative basis by comparing the uncured methacrylate stretching vibration $\left(1638 \mathrm{~cm}^{-1}\right)$ to that of the aromatic ring (1610 $\left.\mathrm{cm}^{-1}\right)$, which serves as internal reference, before (Resin uncured ) and after (Resin cured ) curing. The percentage of residual double bonds was calculated using the following equations:

$$
\begin{aligned}
& \begin{array}{l}
\text { Residual double resin bonds }(\%)=\text { Resin }_{\text {cured }} / \\
\text { Resin }_{\text {uncured, }} \text {, where, }
\end{array} \\
& \text { Resin }_{\text {cured }}=\frac{\text { band area of aliphatic } C=C \text { at } 1640 \mathrm{~cm}^{-1}}{\text { band area of aromatic C } \cdots C \text { at } 1610 \mathrm{~cm}^{-1}} \\
& \text { Resin }_{\text {uncured }}=\text { band area of aliphatic C }=C \text { at } 1640 \mathrm{~cm}^{-1} \\
& \text { band area of aromatic C } \cdots C \text { at } 1610 \mathrm{~cm}^{-1}
\end{aligned}
$$

The following step was to measure the degree of conversion of the resin cement in each root section:

DC $(\%)=100-(\%$ of Residual double resin bonds).

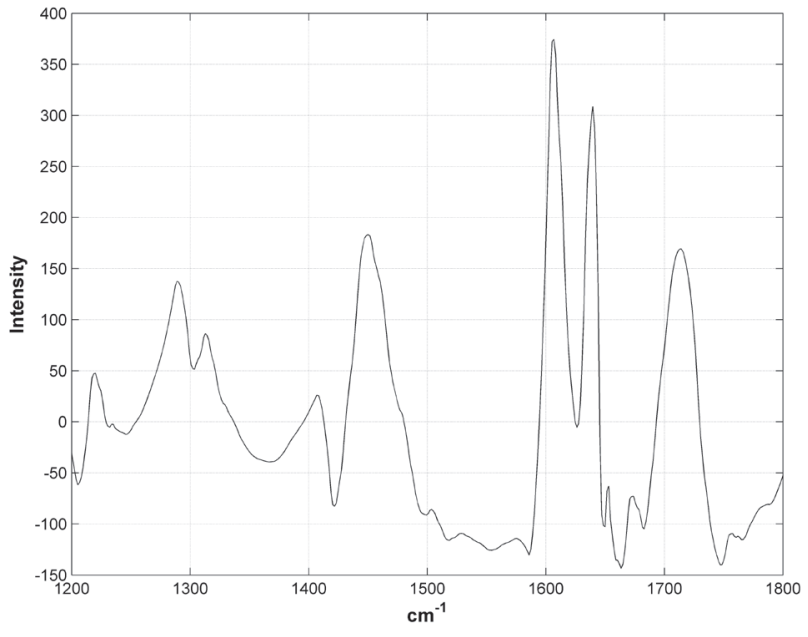

Figure 2- Raman spectra for Duo-link uncured. The $1610 \mathrm{~cm}-1$ and the $1640 \mathrm{~cm}-1$ peaks correspond to the aromatic ring and to the $\mathrm{c}=\mathrm{c}$ bonds of the uncured cement, respectively

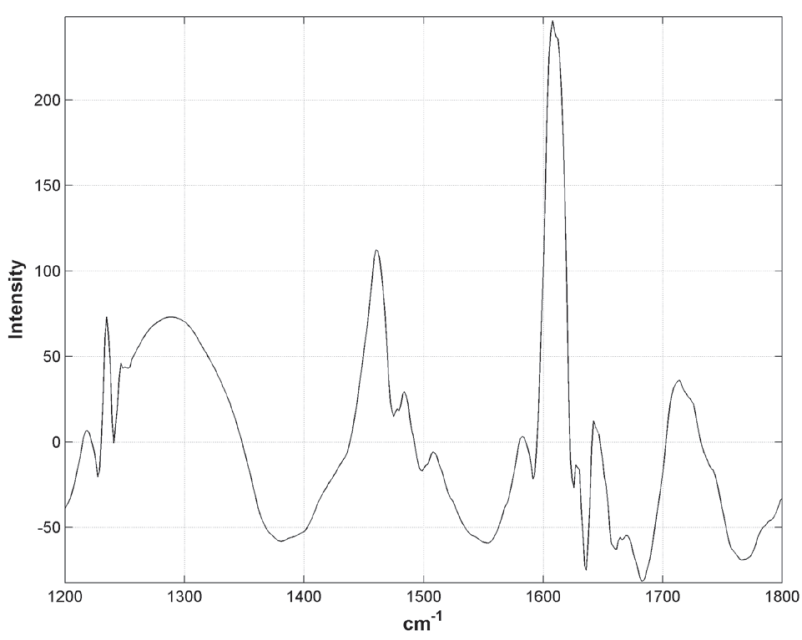

Figure 3- Raman spectra for Duo-link cured cement layer used with All bond 2 (middle region)

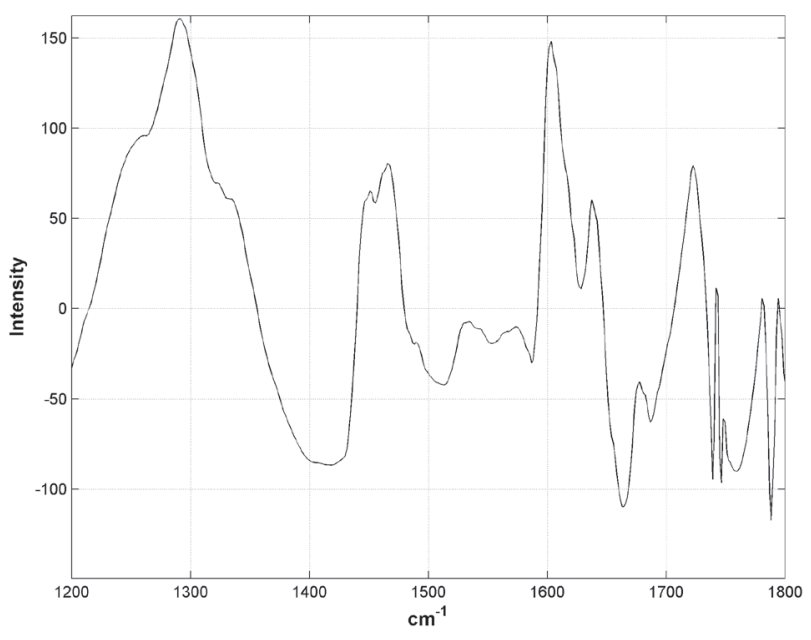

Figure 4- Raman spectra for Duo-link cured cement layer used with Xeno III (middle region) 


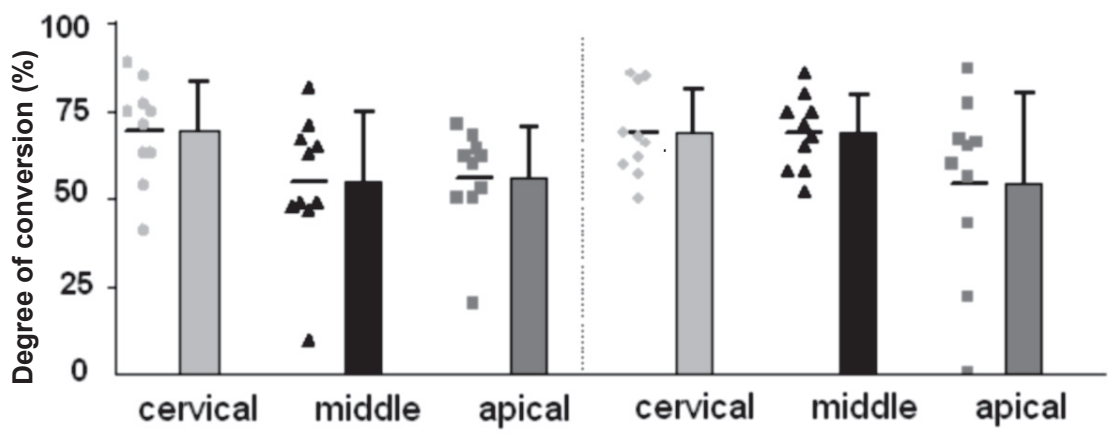

All Bond 2

Xeno III

Figure 5- Degree of conversion values (\%) obtained in 20 specimens ( $n=10)$, according to the adhesive system and post space regions

In order to evaluate the influence of the adhesive and root region on the resin cement degree of conversion, the data, in percentage, were subjected to the repeated measures ANOVA test (RM ANOVA, $p<0.05)$. Tukey's test $(p<0.05)$ was used to compare the mean values in the six experimental conditions.

\section{RESULTS}

The degree of conversion values (Means \pm SD), in percentage, are presented in the dot plot and corresponding column graph (Figure 5).

There was no interaction between the variables "adhesive system" and "root region" (RM ANOVA: $\mathrm{F}_{\mathrm{df}(2 ; 36)}=1.15 ; \mathrm{p}$-valor $\left.=0.33\right)$. Tukey's test $(\mathrm{p}<0.05)$ showed no statistically significant differences between the means: All bond $2_{\text {cervical }}=69.3 \%$, All bond $2_{\text {middle }}=55.1 \%$, All bond $2_{\text {apical }}=56 \%$, Xeno III $_{\text {cervical }}=68.7 \%$, Xeno III middle $=68.8 \%$, Xeno III $_{\text {apical }}=54.3 \%$.

\section{DISCUSSION}

There is a trend to reduce the number of steps necessary to apply adhesives. The simplified adhesives currently in use are the etch-and-rinse with primer and adhesive applied simultaneously (two-step) and the self-etch systems, which contain a self-etch primer and an adhesive in one solution (all-in-one).

The increasing preference for using simplified systems is due to the decrease in chair time. However, using such materials has some drawbacks. Firstly, thin resin layers of these adhesives generate great amounts of uncured acidic monomers ${ }^{1,4,11,16}$, which is a result of the resin not totally cured by the presence of oxygen ${ }^{10}$. It is well known that these monomers can adversely react with the basic amine catalysts of chemically and dual cure composites, retarding the cement polymerization. Secondly, the same adhesive layer inhibited by the oxygen creates an osmotic gradient capable of attracting water that can cause some delay in the resin self cure and/or degrade the adhesive/ cement interface ${ }^{5,16,17}$. Therefore, one should expect a poor polymerization reaction from the combined Xeno III/Duo-link layer, but this was not seen. This results suggests that the suboptimal bond strengths of all-in-one adhesives, rather than a cause of poor resin cement polymerization is due to comparatively more complex interface with dentin ${ }^{18}$, great hidrophilicity ${ }^{5,10}$, hydrolytic instability ${ }^{19}$ and ability to activate latent enzymes of the substrate (MMPs), destroying the collagen fibrils ${ }^{13}$. Recently, a practical way to minimize the effects of simplified adhesive systems has been proposed by Cadenaro, et al. $^{3}$ (2006), who employed longer curing times than those recommended by the manufacturers. Another different approach to improve bonding has been the use of an additional layer of hydrophobic adhesive on the polymerized adhesive layer $^{10}$.

The pendant double bonds is also known (pendant methacrylate groups tied into the network) to lead to increased degree of conversion but not improve physical properties ${ }^{7}$. However, in root canal restorations they must remain trapped to the network and eventually react to increase cement physical properties as these restorations are not exposed to the oral medium, where pendant groups tend to be leached to saliva.

In spite of what was said before, a few specimens from both groups in the present study showed close to zero polymerization. We believe that the presence of residual water (used to cleanse the root canal before hybridization) hampered the degree of conversion in the middle and apical regions, which are very sensitive to moist control ${ }^{6}$.

The problem of resin cement polymerization is further aggravated by the light gradation along the root canal dentin during the post cementation ${ }^{19}$. Nevertheless, our results showed no differences between the degrees of conversion obtained in the three post space regions. The use of a lighttransmitting glass fiber post has been claimed to improve polymerization through the depth of post spaces ${ }^{19}$, explaining the absence of regional 
differences. More recently Kim, et al. $^{9}$ (2009) demonstrated that the degree of conversion of a luting agent depended on the on the light transmission capacity of the posts tested, which suggests that the post herein used was appropriate.

Foxton, et al. ${ }^{8}$ (2005) measured the Knoop hardness in post spaces cemented with dual cure resin cement and found no differences between what they called "cervical" and "apical regions". However, the microhardness test was ineffective for measuring the depth of cure of resins beyond $10 \mathrm{~mm}^{19}$. On the other hand, the micro-Raman analysis was proven an efficient tool to measure the degree of conversion of luting materials in apical regions.

The anticipated hypothesis was rejected. It was found that the two adhesive systems tested can be equally associated to the dual resin cement in root canal restorations. However, other aspects, e.g., resistance to fatigue, bonding strategy to dentin and time in aqueous storage, need to be considered and are of similar importance for the study of durable restorations.

\section{CONCLUSIONS}

No difference on the degree of conversion of the cement was observed between the two tested groups in relation to either the adhesive type or the different dentin zones.

\section{ACKNOWLEDGEMENTS}

This research was supported by FAPESP (05/60700-0), the State of São Paulo Research Foundation (São Paulo, Brazil). Special thanks to Prof. Evaldo José Corat from the National Institute for Space Research (INPE) at São Jose dos Campos (SP, Brazil), for his help with the Raman analysis.

\section{REFERENCES}

1- Aksornmuang J, Nakajima M, Foxton RM, Tagami J. Effect of prolonged photo-irradiation time of three self-etch systems on the bonding to root canal dentine. J Dent. 2006;34:389-97.

2- Bouillaguet S, Troesch S, Wataha JC, Krejci I, Meyer JM, Pashley $\mathrm{DH}$. Microtensile bond strength between adhesive cements and root canal dentin. Dent Mater. 2003;19:199-205.

3- Cadenaro M, Antoniolli F, Sauro S, Tay FR, Di Lenarda R, Prati C, et al. Degree of conversion and permeability of dental adhesives. Eur J Oral Sci. 2006;113:525-30.

4- Cheong C, King NM, Pashley DH, Ferrari M, Toledano M, Tay FR. Incompatibility of self-etch adhesives with chemical/dualcured composites: two-step vs one-step systems. Oper Dent. 2003;28:747-55.

5- Chersoni S, Acquaviva GL, Prati C, Ferrari M, Grandini S, Pashley $\mathrm{DH}$, et al. In vivo fluid movement through dentin adhesives in endodontically treated teeth J Dent Res. 2005;84:223-7.

6- Ferrari M, Mannocci F, Vichi A, Cagidiaco MC, Mjor IA. Bonding to root canal: structural characteristics of the substrate. Am J Dent. 2000;13:255-60.

7- Floyd CJ, Dickens SH. Network structure of Bis-GMA- and UDMA-based resin systems. Dent Mater. 2006;22:1143-9.

8- Foxton RM, Nakajima M, Tagami J, Miura H. Adhesion to root canal dentine using one and two-step adhesives with dual-cure composite core materials. J Oral Rehabil. 2005;32:97-104.
9- Kim YK, Kim SK, Kim KH, Kwon TY. Degree of conversion of dual-cured resin cement light-cured through three fibre posts within human root canals: an ex vivo study. Int Endod J. 2009;42:667-74.

10- King NM, Tay FR, Pashley DH, Hashimoto M, Ito S, Brackett WW, et al. Conversion of one-step to two-step self-etch adhesives for improved efficacy and extended application. Am J Dent. 2005; 18:126-34.

11- Latta MA, Kelsey WP 3rd, Kelsey WP 5th. Effect of polymerization mode of adhesive and cement on shear bond strength to dentin. Am J Dent. 2006;19:96-100.

12- Mannocci F, Pileck P, Bertelli E, Watson TF. Density of dentinal tubules affects the tensile strength of root dentin. Dent Mater. 2004;20:293-6.

13- Nishitani $Y$, Yoshiama M, Wadgaonkar B, Breschi L, Manello F, Mazonni $A$, et al. Activation of gelatinolytic/collagenolytic activity in dentin by self-etching adhesives. Eur J Oral Sci. 2006;114:1606.

14- Pianelli C, Devaux J, Bebelman S, Leloup G. The microRaman spectroscopy, a useful tool to determine the degree of conversion of light-activated composite resins. J Biomed Mater Res. $1999 ; 48: 675-81$.

15- Sigemori RM, Reis AF, Giannini M, Paulillo LA. Curing depth of a resin-modified glass ionomer and two resin-based luting agents. Oper Dent. 2005;30:185-9.

16- Suh BI, Feng L, Pashley DH, Tay FR. Factors contributing to the incompatibility between simplified-step adhesives and selfcured or dual cured composites. Part III. Effect of acidic resin monomers. J Adhes Dent. 2003;5:267-82.

17- Tay FR, Suh BI, Pashley DH, Prati C, Chuang S, Li F. Factors contributing to the incompatibility between simplified-step adhesives and self-cured or dual cured composites. Part II. Single bottle, total etch adhesive. J Adhes Dent. 2003;5:91-105.

18- Wang $Y$, Spencer P. Physiochemical interactions at the interfaces between self-etch adhesive systems and dentine. J Dent. 2004;32:567-79.

19- Yoldas O, Alaçam T. Microhardness of composites in simulated root canals cured with light transmitting posts and glass-fiber reinforced composite posts. J Endod. 2005;31:104-6. 
The article "The adhesive system and root canal region do not influence the degree of conversion of dual resin cement" published at Journal of Applied Oral Science 18(5):477-81 was printed with errors, which were corrected as follows:

Pag. 477

" (...) at 12-mm-deep post space preparation and a fiber post (D T Light Post, Bisco) (...)" should be read " (...) at 12-mm-deep post space preparation and a fiber post (FRC Postec, Ivoclar) (...)".

Pag. 478

" (...)calibrated drill (size 2) of a tapered quartz- FRC post system (FRC Postec, Ivoclar, Schaan, Lichtenstein) at a working length (...)" should be read " (...) calibrated drill (size 2) of a glass- FRC post system (FRC Postec, Ivoclar, Schaan, Lichtenstein) at a working length (...)" 